\title{
Language, executive functioning and symptomatology- Is fluency a transversal tool in schizophrenia?
}

\author{
Romina Rinaldi, Laurent Lefebvre, Julie Trappeniers \\ Cognitive Sciences, Research Institute for Health Sciences and Technology, Université de Mons (UMONS), Mons, Belgium \\ Email: Romina.Rinaldi@umons.ac.be
}

Received 3 July 2013; revised 2 August 2013; accepted 9 August 2013

Copyright (C) 2013 Romina Rinaldi et al. This is an open access article distributed under the Creative Commons Attribution License, which permits unrestricted use, distribution, and reproduction in any medium, provided the original work is properly cited.

\begin{abstract}
Despite a large number of studies on fluency disorders in schizophrenia, it is still not clear whether executive functioning and fluency tasks are empirically linked and how symptomatology could specifically get involved on these influences. We carried out analyses of performances in several verbal fluency tasks, a non-verbal fluency task and an executive test (FAB) in 25 schizophrenics and 25 healthy subjects matched in terms demographic data. Patients also completed the Positive and Negative Symptoms Scale in order to control for their clinical profile. Our results suggest that schizophrenic patients show both category and letter fluency deficits with a greater impairment for letter fluency. They also display poorer performances for the non-verbal fluency task. In patients, all the verbal and non-verbal fluencies are significantly correlated with the FAB total score. By contrast, in controls, only letter fluency correlates with the FAB total score, which is congruent with previous literature on the healthy mechanisms of verbal fluency. Besides, factorial analyses show that symptomatology is specifically related to particular indexes of fluency tasks. Taken together, these data lead to support the hypothesis of retrieval rather than semantic difficulties and alargest involvement of executive functioning in schizophrenics during tasks that require a certain degree of efficiency, with performance being influenced by the clinical profile. Yet, the relation between fluency scores and executive functioning has to be more intensively explored and further studies should include semantic memory measures that fit with pathology's constraints and characteristics.
\end{abstract}

Keywords: Schizophrenia; Executive Functions; Symptomatology; Fluency

\section{INTRODUCTION}

Verbal fluency tasks require the subject to produce as many words as he can within a given time (one or two minutes) based on a given criteria, which can be a semantic category (e.g. animals) or a letter (e.g. words that begin with "p"). These two types of fluency may not be equivalent in terms of mental processes and resources. Some authors highlighted the fact that category fluency specifically assesses the semantic memory and semantic retrieval while phonemic fluency is rather linked with executive abilities (i.e. mental flexibility and inhibition). Possibly because in phonemic fluency, subjects are only given a letter and they have to search in many categories to find words that match with the instruction [1]. These assumptions are supported by data suggesting that verbal fluency tasks are strongly linked with left frontal cortex activation but also to a lesser extent with left temporal cortex activation (mainly in the context of the category fluency) [2]. Verbal fluency tasks may also be analyzed by considering two indexes revealing two main strategies during task resolution. The first index is the cluster which implies the production of two or more words of a semantic (e.g. domestic animals for the animal criterion) or phonemic (e.g. two or more words beginning with the syllable "po" for the "beginning with a p" criterion) subcategory. Clustering requires a research into one phonemic or semantic subcategory while switching (and switches) reveals the fact of changing from a subcategory to another when the first one is exhausted. As different types of verbal fluency seem to require different abilities, clusters and switches also involve specific competences. Clustering is supposed to involve the use of semantic categories stored in semantic memory and/or a phonemic analysis. These categories can be evaluated by calculating the size of clusters or by interpreting mistakes, which can reflect some inhibition disorders. At a different level, switches involve mental flexibility [3]. 
Moreover, fluency assessment can be specified with a non-verbal fluency task, which requires the subject to draw as many different abstract figures as he can by connecting points (that are arranged like on a dice) with straight lines ([4-6]). Impairments on this task could be linked with brain dysfunctions, in particular in patients with Parkinson's disease [7] irrespective of their visuomotor and visuospatial skills [8].

It is widely acknowledged that schizophrenics display verbal fluency troubles [9], with disproportionate impairments on category fluency $([2,9-11])$ that result in the production of words that are acquired earlier and more exemplars of the category [12]. Although we may think that fluency disorders are linked with a general linguistic problem, they equally seem to be part of a broader executive problematic. Verbal fluency is indeed fundamentally different from spontaneous and automatic speech [13] and requires various processes going from the lexical selection and the phonemic encoding to working memory and cognitive control abilities $([1,14])$.

In the field of schizophrenics' verbal fluency impairments, there is still a large debate on troubles that are at the origins of those difficulties. Two hypotheses are then made; namely a disorganized storage of semantic information on the one hand, and retrieval difficulties on the other hand. In their meta-analysis of letter and category fluency in schizophrenia, Reference [10] shows that semantic fluency is more impaired than phonemic fluency and suggests that a compromised semantic system could be the core of these impairments. Their results are supported by another meta-analysis [15] that underlines a greater deficit of semantic fluency in schizophrenia and argues for to the involvement of a generalized intellectual (not an executive) deficit linked to a poorer education and a compromised semantic store. Some other studies claim that retrieval issue may rather explain verbal fluency impairments ([11,16-18])

However, scopes are not confined to the two options we mentioned, the results are much more heterogeneous and influenced by many variables. Among these, we can list general variables like age at the onset of the illness [9], age of the subjects or evolution of the pathology $([19,20])$; task-specific variables as the language used during the testing [21]; or more schizophrenics 'specific variables such as symptomatology $([2,22])$. Furthermore, the word "fluency" has a really large meaning which includes many different forms of testing in terms of instructions, time, etc.

Particularly, symptomatology is an interesting variable to take into account. Many authors have already highlighted its impact on cognitive and verbal fluency performances $([2,23,24])$. In particular, some disorganization symptoms as formal thought disorders ([2,25]), some positive symptoms as delusions [26], negative symptoms in general ([22,27-29]) or the lack of insight [30] are specifically linked with verbal fluency performances in schizophrenics. In his model of action and selfmonitoring, Frith underlines that verbal fluency is a privileged way to assess inhibition and regulation of action. According to him, schizophrenics with negative symptoms should produce fewer words in verbal fluency, due to the fact that they have difficulties to initiate spontaneous behaviors; while schizophrenics with positive symptoms should make more perseverations and rule breaks because of their difficulties to regulate their actions and inhibit inappropriate behaviors [24].

To summarize, what is true and commonly admitted for healthy subjects concerning the executive part of verbal fluency remains questionable in schizophrenics. Actually, even if some studies have emphasized the relation between verbal fluency and executive functions in schizophrenia as a secondary feature ([18]) or as a common criterion for early diagnosis $([31,32])$, it is not clear yet whether executive functioning (as a specific part of cognition) and fluency tasks are empirically linked. Furthermore, if we consider that these links exist, are they also valid for the non-verbal fluency task?

The aim of our study is to clarify the link between fluency and global executive efficiency with an innovative experimental device including rapid and accurate tools.

\section{METHODS}

\subsection{Participants}

Twenty-five French-speaking subjects meeting the DSMIV [33] diagnostic criteria for schizophrenia (from prior psychiatric expertise) were recruited in several mental health care services (see Table 1 for demographic data). Patients were carefully screened and those with drug abuse and neurological or vascular past histories were excluded, as were schizoaffective patients. All patients are under medication and are hospitalized during the assessment period. They are qualified as "stable" (in terms of symptoms, medication and behavior in an assessment context). They are not in a florid or residual phase of the pathology. Sociocultural level is estimated with the number of school years accomplished since the first grade. The control group consisted of 25 healthy people matched in terms of age, gender and schooling with schizophrenic subjects. Exclusion criteria for this group included non-native speakers, diagnosed mental illness, neurological or vascular past histories, drug abuse and chronic medication.

\subsection{Material and Study Design}

\subsubsection{Fluency Tasks}

Fluency tasks part was constituted with verbal fluency 
Table 1. Demographic data.

\begin{tabular}{|c|c|c|c|c|c|c|c|}
\hline & & \multicolumn{2}{|c|}{ Controls } & \multicolumn{2}{|c|}{ Schizophrenics } & & \\
\hline & & \multicolumn{2}{|c|}{$\mathbf{N}$} & \multicolumn{2}{|c|}{$\mathbf{N}$} & & \\
\hline \multirow{4}{*}{ Gender } & Total & \multicolumn{2}{|c|}{25} & \multicolumn{2}{|c|}{25} & & \\
\hline & Male & \multicolumn{2}{|c|}{16} & \multicolumn{2}{|c|}{16} & & \\
\hline & Female & \multicolumn{2}{|c|}{9} & \multicolumn{2}{|c|}{9} & & \\
\hline & & Mean & S.D. & Mean & S.D. & $\mathbf{F}$ & p value \\
\hline Age & & 38.76 & 11.30 & 38.96 & 11.62 & 0.004 & 0.951 \\
\hline \multirow[t]{2}{*}{ Schooling } & & 11.36 & 2.02 & 11.48 & 2.14 & 0.042 & 0.839 \\
\hline & & & & Mean & S.D. & & \\
\hline General psychopathology & & & & 50.12 & 10.71 & & \\
\hline Positive scale score & & & & 26.44 & 6.72 & & \\
\hline Negative scale score & & & & 24.76 & 5.74 & & \\
\hline Positive factor score & & & & 24.08 & 6.38 & & \\
\hline Negative factor score & & & & 25.72 & 7.53 & & \\
\hline Disorganization factor score & & & & 23.64 & 6.79 & & \\
\hline Core negative symptoms & & & & 19.24 & 5.15 & & \\
\hline Social amotivation & & & & 10.72 & 3.63 & & \\
\hline \multirow[t]{2}{*}{ Duration of illness } & & & & 11.64 & 9.88 & & \\
\hline & & \multicolumn{6}{|c|}{$\mathbf{N}$} \\
\hline \multirow[t]{2}{*}{ Symptomatological profile } & Negative & \multicolumn{6}{|c|}{10} \\
\hline & Positive & \multicolumn{6}{|c|}{15} \\
\hline
\end{tabular}

tasks [34] that comprise with two category fluencies (categories: animal and fruits/vegetables) and two letter fluencies (letter: "p" and " $r$ "). Each fluency task lasts two minutes. We also used the Five-point test as nonverbal fluency task. In this task, subjects are asked to link at least two points (min. 2 points, max. 5 points) with one or several straight lines in order to produce as many different abstract figures as possible within one minute (see Figure 1).

For the verbal tasks we computed several indexes as totals (total words produced for each category or letter fluency, and totals for category fluency and total for letter fluency scores), number of clusters, number of switches, average number of perseverations, rules break, latency (time before the first answer) and words per 15 seconds interval (output score). We also focused on the performance over the first and the second minute of production. We argue that word production during the first minute may reflect automatic processes of semantic information. The subject should then produce words that are overactivated by the instruction (category or letter), supposedly category exemplars or words with a high frequency. While, during the second minute, subjects are required to develop willful strategies in order to further explore their semantic network. Finally, for the non-verbal task, we computed a total score (number of unique designs) and the number of errors (repetitions of the same figure).

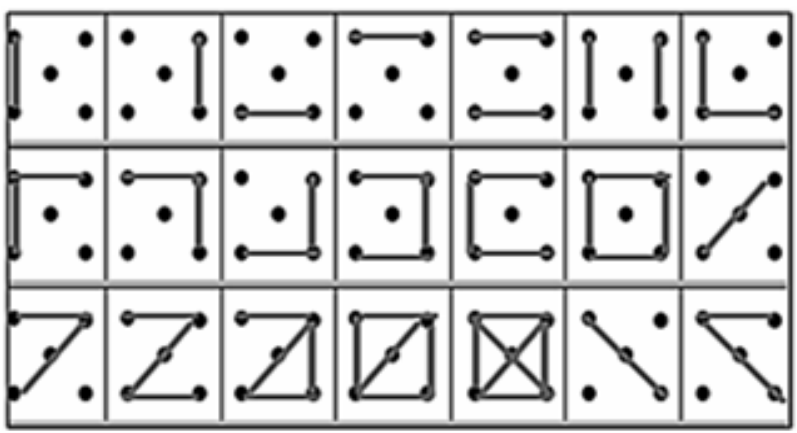

Figure 1. Example of a filled protocol of the five point test.

\subsubsection{Executive Assessment}

Executive assessment was constituted by the Frontal Assessment Battery [35]. The FAB assesses the frontal and executive functioning in healthy and pathological populations. It consists of 6 subtests that evaluate a specific executive component (conceptualization/reasoning, mental flexibility, inhibition, environmental autonomy, interference sensitivity and motor programming). The FAB allows a rapid screening of the executive functioning, is significantly correlated with classical neuropsychological tests (such as WSCT, Stroop test or Mattis Scale) [36], has good metric properties [35], helps differentiate clinical populations [35] including schizophrenics [37] and is correlated with perfusion intensity (SPECT) on the medial and dorsolateral regions of frontal cortex [36]. The 
speed of execution of the FAB enables the experimenter to avoid tiredness or motivation and state changes.

\subsubsection{Clinical Assessment}

Schizophrenics were also tested with the Positive and Negative Symptomatology Scale [38] through the completion of the SCI-PANSS semi-structured interview [39]. We filled the missing points by collecting opinions of the medical and curing staff. Several indexes were then computed. They comprise scale scores (positive scale, negative scale and general psychopathology scale), factor scores (positive factor, negative factor and disorganization factor). The factors arise from the factorial analyses who divide the PANSS into five main components according to the items of the three different scales [40]. The positive factor is computed by summing the following items: delusion, hallucination, unusual thoughts, grandiosity, somatic concerns and suspiciousness; the negative factors, by summing the items relative to passive social withdrawal, emotional withdrawal, blunted affect, lack of spontaneity, poor rapport, disturbance of volition, preoccupation and psychomotor retardation. Finally, the disorganization/cognitive factor is computed by summing the items: cognitive disorganization, difficulties with abstract thought, stereotyped thoughts, poor attention, lack of insight, mannerisms and posturing, and tension. We also computed two negative subfactor scores (corenegative symptoms and social amotivation symptoms). They are used to deepen the analysis of potential symptomatology implications of the negative symptoms by differentiating expressive symptoms that are the core of the negative psychopathology (computed by summing the items: avolition, mannerisms and posturing, motor retardation, flat affect, poor rapport and lack of spontaneity), from those related to community issues (computed by summing the items: passive withdrawal, emotional withdrawal and active social avoidance) [41]. Negative symptoms may indeed have more influence on the skills related to efficiency ([24,38]), while positive and disorganization symptoms may be rather linked with errors [22].

\subsection{Procedure}

Our project has been approved by the ethical committee of each hospital and subjects were asked to read and sign an agreement paper of informed consent. Data were collected in an office with the exclusive presence of the evaluator and the patient. No audio or video tracks were recorded.

\subsection{Statistical Analyses}

All statistical analyses were performed using the software SPSS 17 for Windows with a statistical threshold fixed at $\mathrm{p}<0.05$. Normal distribution of data was verified with the Kolmogorov-Smirnov test for one sample. In order to investigate significant differences between groups, we used one-way ANOVA. Group differences on non-normally distributed data (mean latencies, mean perseverations, mean rules break, words per $15 \mathrm{sec}$ interval, reasoning and non-verbal fluency errors) were analyzed using the non-parametric Mann-Whitney U test. Differences between the performances on the first or the second minute of verbal fluency were searched using the procedure of Cohen's $d$ ' effect size for the intragroup differences; intergroup differences were then searched using a t-test for paired samples. Correlations were searched using the $r$ of Bravais-Pearson. Finally, factor analysis (Principal Component Analysis with Varimax rotation) was used for the schizophrenics in order to better understand the interrelations between fluency, executive functions and symptomatology components.

\section{RESULTS}

\subsection{Intergroup Comparisons}

Results show that experimental subjects produce significantly fewer words for the category $(\mathrm{F}=101.49, \mathrm{p}<$ $0.001)$ and letter fluency $(\mathrm{F}=100.27, \mathrm{p}<0.001)$, fewer words per 15 seconds interval $(\mathrm{z}=-6.041, \mathrm{p}<0.001)$, fewer clusters $(\mathrm{F}=18.36, \mathrm{p}<0.001)$ and fewer switches $(\mathrm{F}=15.201, \mathrm{p}<0.001)$. Nevertheless, they don't make more perseverations $(\mathrm{z}=-0.572, \mathrm{p}=0.567)$ or rule breaks $(\mathrm{z}=-1.829, \mathrm{p}=0.067)$ and don't show longer latencies $(\mathrm{z}=-1.365, \mathrm{p}=0.172)$. Besides, as in controls $\left(d^{\prime}=1.63\right.$, effect size $\left.=0.63\right)$, schizophrenics display greater impairments for letter than for category fluency with a medium effect size $\left(\mathrm{d}^{\prime}=1.35\right.$, effect size $\left.=0.56\right)$. With regard to the automatic versus controlled processes, schizophrenics show better performances for the first than the second minute of production for the animal $(\mathrm{t}=5.751$, $\mathrm{p}<0.001, \mathrm{~d}^{\prime}=2.35$, effect size $\left.=0.76\right)$, fruits and vegetables $\left(\mathrm{t}=7.429, \mathrm{p}<0.001, \mathrm{~d}^{\prime}=1.96\right.$, effect size $\left.=0.70\right)$, letter $\mathrm{p}\left(\mathrm{t}=6.683, \mathrm{p}<0.001, \mathrm{~d}^{\prime}=1.65\right.$, effect size $\left.=0.63\right)$ and letter $\mathrm{r}\left(\mathrm{t}=6.410, \mathrm{p}<0.001, \mathrm{~d}^{\prime}=1.63\right.$, effect size $=$ $0.63)$ fluencies. Controls display a similar profile for animal $\left(\mathrm{t}=5.751, \mathrm{p}<0.001, \mathrm{~d}^{\prime}=1.55\right.$, effect size $\left.=0.61\right)$, fruits and vegetables $\left(\mathrm{t}=7.025, \mathrm{p}<0.001, \mathrm{~d}^{\prime}=1.85\right.$, effect size $=0.68)$, letter $\mathrm{p}\left(\mathrm{t}=5.242, \mathrm{p}<.001, \mathrm{~d}^{\prime}=1.48\right.$, effect size $=0.59)$ and letter $r$ fluency $(\mathrm{t}=9.438, \mathrm{p}<$ $0.001, \mathrm{~d}^{\prime}=1.89$, effect size $\left.=0.69\right)$. However, we see a clearer distinction in schizophrenics, showing greater effect sizes on category than letter fluency, while in controls the effect sizes show little variance and are consistent between the category and letter fluency. Patients also still perform worse than controls for the automatic processes/first minute of production (animals: $\mathrm{F}=42.057, \mathrm{p}<$ 
0.001; fruits and vegetables: $\mathrm{F}=40.585, \mathrm{p}<0.001$; letter $\mathrm{p}: \mathrm{F}=39.928, \mathrm{p}<0.001$; letter $\mathrm{r}: \mathrm{F}=52.024, \mathrm{p}<0.001)$ and for the control processes/second minute of production (animals: $\mathrm{F}=55.164, \mathrm{p}<0.001$; fruits and vegetables: $\mathrm{F}$ $=45.058, \mathrm{p}<0.001$; letter $\mathrm{p}: \mathrm{F}=54.487, \mathrm{p}<0.001$; letter $\mathrm{r}: \mathrm{F}=47.131, \mathrm{p}<0.001)$.

Concerning the Five-Point Test, schizophrenics produce fewer unique designs $(\mathrm{F}=50.259, \mathrm{p}<0.001)$ and more perseveration errors $(\mathrm{z}=-3.050, \mathrm{p}=0.002)$.

They also show lower performances for the FAB total score $(\mathrm{F}=109.304, \mathrm{p}<0.001)$ and five of the six subtests; namely mental flexibility $(\mathrm{F}=39.63, \mathrm{p}<0.001)$, motor programming $(\mathrm{F}=50.45, \mathrm{p}<0.001)$, inhibition $(\mathrm{F}$ $=33.75, \mathrm{p}<0.001)$, reasoning $(\mathrm{z}=-5.145, \mathrm{p}<0.001)$ and interference sensitivity $(\mathrm{F}=16.69, \mathrm{p}<0.001)$. The "environmental autonomy" subtest doesn't breed any intergroup differences $(\mathrm{z}=-1.00, \mathrm{p}=0.317)$. Further- more, this score reach a ceiling effect in both groups.

\subsection{Correlations}

Correlations values are listed in Tables 2 (for the control group) and $\mathbf{3}$ (for the schizophrenic group). Neither age nor educational level had significant influences on verbal fluency, non-verbal fluency or total FAB. In the control group, results show significant correlations between letter fluency and FAB $(r=0.512, p=0.009)$ and between verbal fluencies (letter and category fluencies) $(r=0.479$, $\mathrm{p}=0.015$ ). Nevertheless, the FAB score reaches a ceiling effect in the control group, as the majority of subjects obtain the maximum total score. Anyway, the significant correlation between this score and the phonemic fluency score must not be ignored, mostly because it does not appear for any other type of fluency. By contrast, in schizophrenics, analyzes show significant correlations

Table 2. Correlation values in controls.

\begin{tabular}{|c|c|c|c|c|c|c|c|}
\hline & & Age & Schooling & Category fluency & Letter fluency & Non-verbal fluency & FAB total \\
\hline \multirow{2}{*}{ Age } & $\mathrm{r}$ & & 0.025 & 0.000 & 0.068 & -0.350 & 0.012 \\
\hline & $\mathrm{p}$ value & & 0.905 & 0.996 & 0.747 & 0.086 & 0.955 \\
\hline \multirow{2}{*}{ Schooling } & $\mathrm{r}$ & & & 0.155 & 0.120 & 0.007 & 0.299 \\
\hline & $\mathrm{p}$ value & & & 0.459 & 0.567 & 0.974 & 0.146 \\
\hline \multirow{2}{*}{ Category fluency } & $\mathrm{r}$ & & & & $0.479^{*}$ & 0.300 & 0.229 \\
\hline & $\mathrm{p}$ value & & & & 0.015 & 0.145 & 0.270 \\
\hline \multirow{2}{*}{ Letter fluency } & $\mathrm{r}$ & & & & & 0.264 & $0.512^{* *}$ \\
\hline & $\mathrm{p}$ value & & & & & 0.203 & 0.009 \\
\hline \multirow{2}{*}{$\begin{array}{c}\text { Non-verbal } \\
\text { fluency }\end{array}$} & $\mathrm{r}$ & & & & & & 0.123 \\
\hline & $\mathrm{p}$ value & & & & & & 0.558 \\
\hline FAB total & $\mathrm{p}$ value & & & & & & \\
\hline
\end{tabular}

Table 3. Correlation values in schizophrenics.

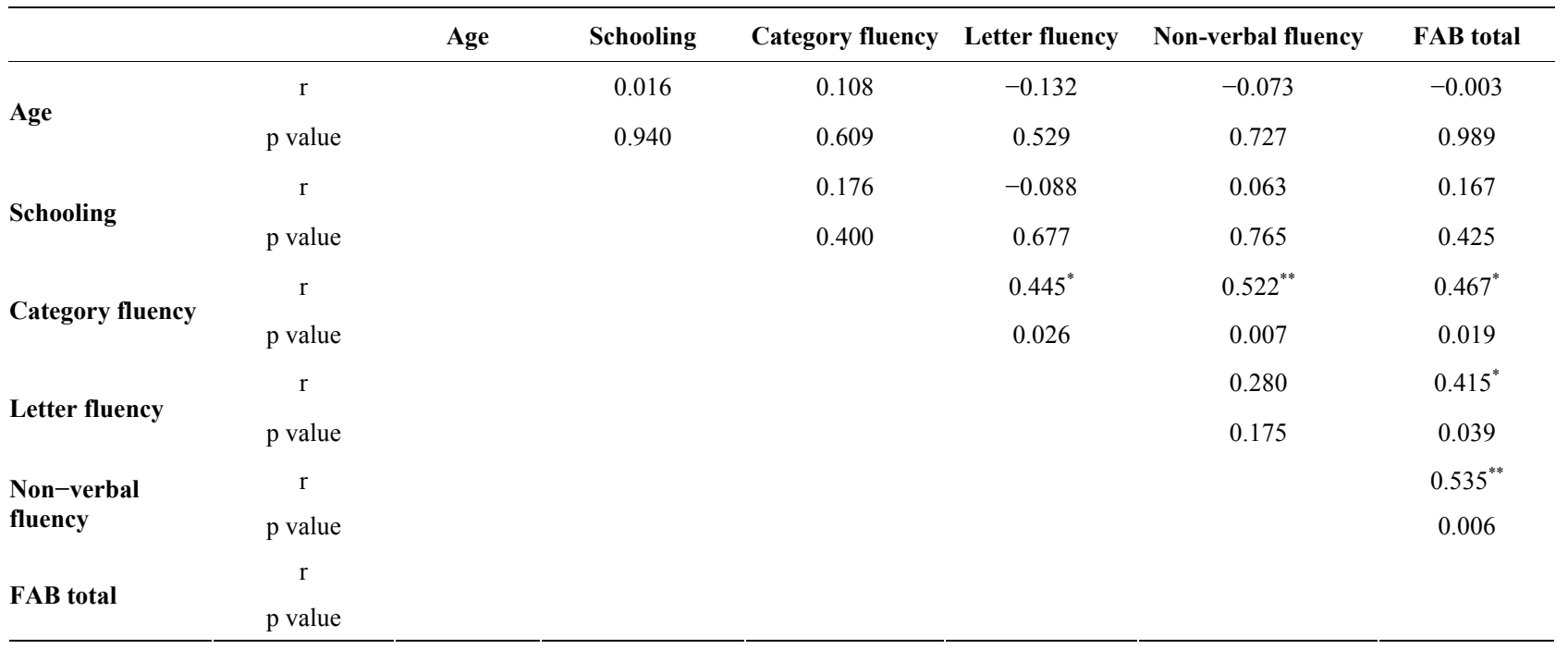


between FAB and category fluency $(r=0.467, p=0.019)$, letter fluency $(r=0.415, p=0.039)$ and non-verbal fluency $(r=0.535, p=0.006)$, but also between category and non-verbal fluencies $(r=0.522, p=0.007)$ and between verbal fluencies $(\mathrm{r}=0.445, \mathrm{p}=0.026)$.

\subsection{Factor Analysis}

We computed the PCA by including verbal fluencies totals, non-verbal fluency number of unique designs and errors, total FAB, FAB subtests scores (reasoning, interference, inhibition, motor programming, environmental autonomy and mental flexibility), PANSS scale score (general psychopathology scale, positive scale and negative scale), PANSS factor scores (positive factor, negative factor and disorganization factor), core negative symptoms and social amotivation scores, and duration of illness. Despite the small sample of patients, PCA was lead because of statistical analyses showing satisfying communalities (see Table 4).

We kept three axes explaining $61.33 \%$ of the scatterplot variance. Figures 2 and $\mathbf{3}$ represent the scatter plot in the plans $1-2$ and $1-3$ and correlations variables/ of variables (correlation coefficients with factors) give information about the quality and reliability of each vari-

Table 4. Communalities of the 20 variables introduced for factor analyses.

\begin{tabular}{lc}
\hline Variables & Extraction \\
\hline category fluency & 0.736 \\
letter fluency & 0.637 \\
non-verbal fluency & 0.622 \\
total FAB & 0.926 \\
Reasoning & 0.604 \\
mental flexibility & 0.738 \\
motor programming & 0.772 \\
Inhibition & 0.712 \\
environmental autonomy & 0.556 \\
Interference & 0.812 \\
non-verbal fluency errors & 0.656 \\
general psychopathology scale & 0.846 \\
positive scale & 0.850 \\
negative scale & 0.952 \\
positive factor & 0.912 \\
negative factor & 0.905 \\
disorganization factor & 0.884 \\
negative core symptoms & 0.859 \\
social amotivation & 0.755 \\
duration of illness & 0.654 \\
\hline Extacion me P &
\end{tabular}

Extraction method: Principal Component Analyses. able with the considered factor. For our data, the factor can be found in Table 5. Factorial coordinates better represented variables are the positive factor score for the factor $1\left(\mathrm{r}=0.879, \mathrm{r}^{2}=0.772\right)$, the negative factor score for the factor $2\left(r=0.884, r^{2}=0.781\right)$ and the total FAB score for the factor $3\left(r=0.846, r^{2}=0.716\right)$. The interpretation of variables that correlate with a value of less than 0.5 with a factor must be considered with prudence.

Regarding Figure 2, factor 1 shows a clear distinction between the positive sides of the pathology and fluency and executive scores; the opposition being more sharp for non-verbal fluency 'number of unique designs, inhibition, interference, motor programming and environmental autonomy. Factor 2 shows an even sharper opposition between negative symptomatology and the positive ones, on the one hand; but also with all the fluency and executive measures, on the other hand. This may imply that negative factor has a stronger effect on fluency, and especially on category fluency. Figure $\mathbf{3}$ exposes a clear opposition between the FAB scores and all the other variables, suggesting that a good level of executive functions may prevent a subject from fluency impairments and negatively correlates with all schizophrenics 'symptoms.

Regarding the matrix of correlations between variables and factors, we can raise more specific links. So, we can see negative correlations between the positive symptomatology and severity of illness with non-verbal fluency and interference on the factor 1 , between negative symptoms and category fluency on factor 2 , and positive correlations between executive measures and the three types of fluency (category, letter and non-verbal fluency) on the factor 3 .

Nevertheless, considering the low proportion of strong correlations between variables and factors, these data must remain indicative and be interpreted with caution.

\section{DISCUSSION}

The present study aimed to analyze the link between executive dysfunction, fluency performances and symptomatology in schizophrenia. The results show that schizophrenics have, as expected, lower scores for the verbal and non-verbal fluency tasks and for the executive assessment battery (FAB). These results are consistent with previous studies concerning verbal fluency $([9,10,15,42])$ or executive functioning $([43,44])$ in schizophrenics. Non-verbal fluency has never been deeply investigated so far in schizophrenics. Nevertheless, our results show that this type of fluency is also significantly impaired in this group. This could support the general idea according to which fluency impairments are not properly linguistic (even semantic) issues in schizophrenia; in contrast with 


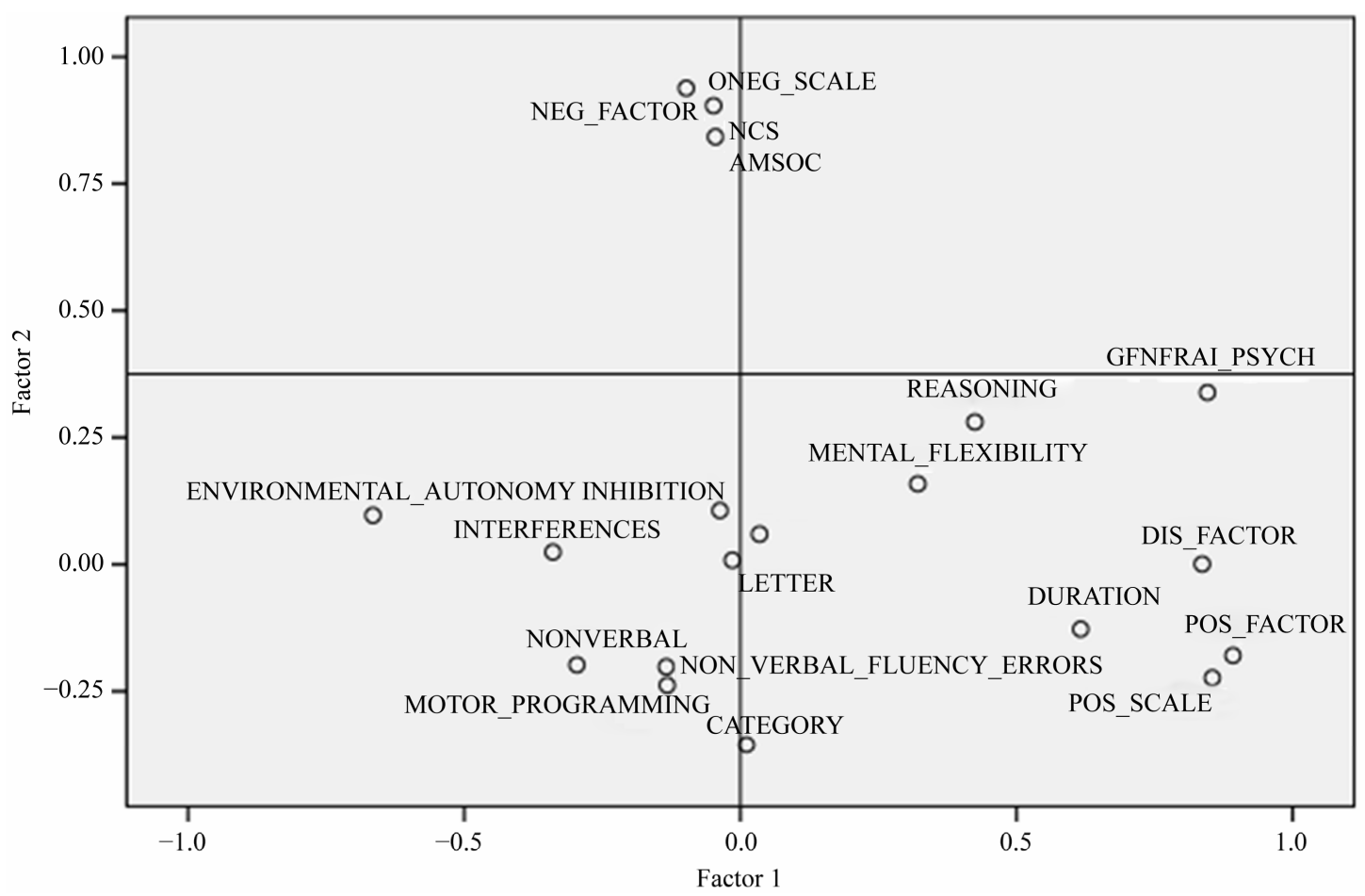

Figure 2. PCA scatterplot in the plan factor $1 /$ factor 2 .

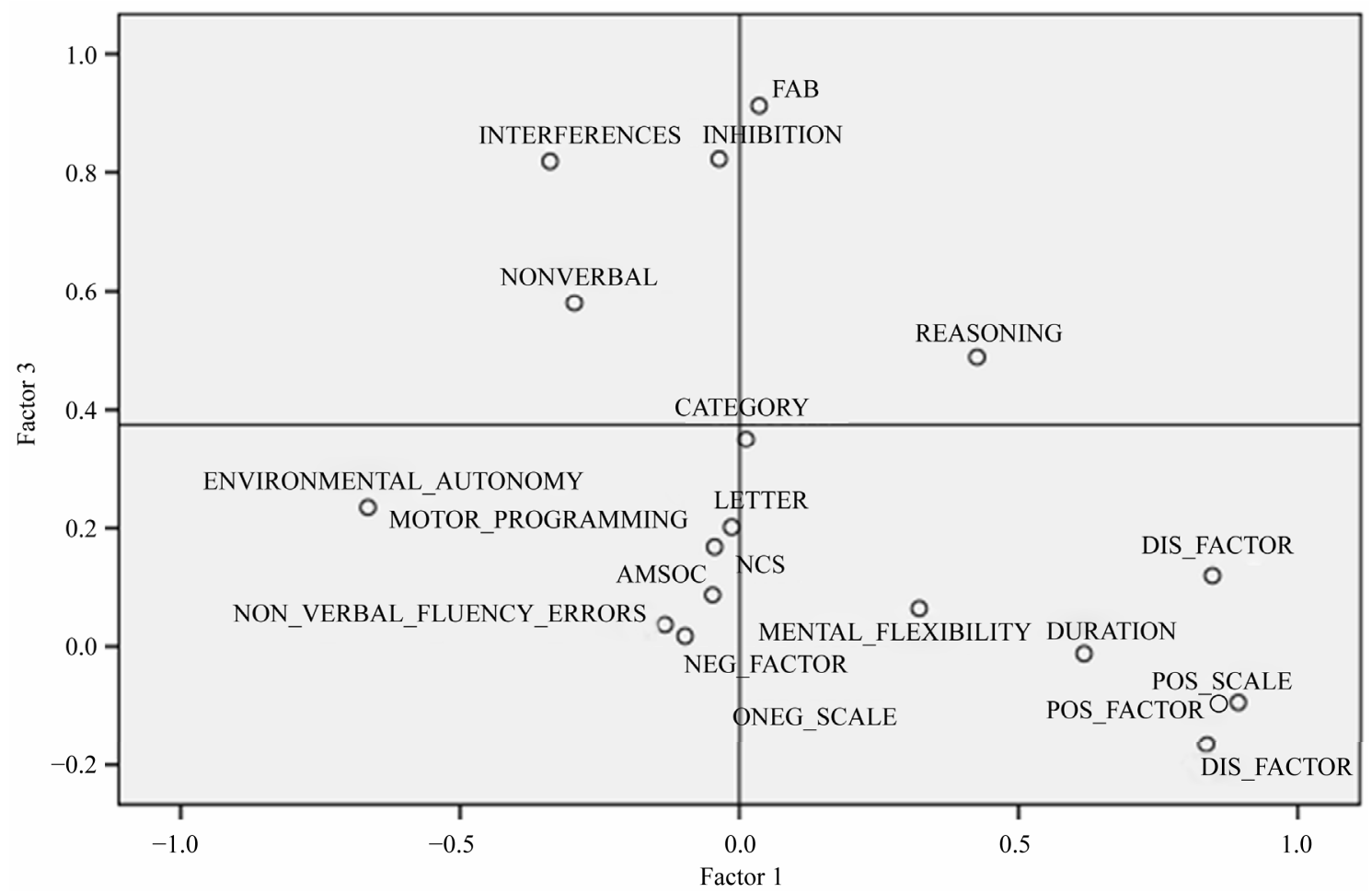

Figure 3. PCA scatterplot in the plan factor 1 /factor 3 .

what reference [10] claims.

According to this, one can say that the first limit of this study is that it does not involve linguistic measures. We don't aim to deny the fact that linguistic variables are involved in verbal fluency tasks in schizophrenia. Nevertheless, we do not know yet the nature of these variables. As Frith claims, linguistic measures, because of cognitive impairments, are fundamentally skewed on 
Table 5. PCA variables-factors correlations.

\begin{tabular}{|c|c|c|c|c|c|}
\hline & Factor 1 & Factor 2 & & Factor 3 & \\
\hline category fluency & -0.025 & -0.494 & & 0.611 & \\
\hline letter fluency & -0.061 & -0.140 & & 0.595 & \\
\hline Non-verbal fluency & -0.423 & -0.389 & & 0.539 & \\
\hline total FAB & -0.341 & -0.088 & & 0.846 & \\
\hline Reasoning & 0.143 & 0.333 & & 0.536 & \\
\hline mental flexibility & & & 0.256 & 0.102 & 0.621 \\
\hline motor programming & & & -0.229 & -0.296 & -0.068 \\
\hline Inhibition & & & -0.395 & -0.015 & 0.617 \\
\hline environmental autonomy & & & -0.689 & -0.125 & 0.095 \\
\hline Interference & & & -0.610 & -0.169 & 0.586 \\
\hline Non-verbal fluency errors & & & 0.007 & -0.197 & 0.061 \\
\hline general psychopathology scale & & & 0.610 & 0.508 & 0.407 \\
\hline positive scale & & & 0.864 & -0.032 & 0.321 \\
\hline negative scale & & & -0.216 & 0.896 & 0.074 \\
\hline positive factor & & & 0.879 & 0.007 & 0.364 \\
\hline negative factor & & & -0.330 & 0.884 & 0.042 \\
\hline disorganization factor & & & 0.755 & 0.187 & 0.144 \\
\hline negative core symptoms & & & -0.312 & 0.868 & 0.049 \\
\hline social amotivation & & & -0.338 & 0.759 & 0.206 \\
\hline duration of illness & & & 0.633 & 0.049 & 0.226 \\
\hline
\end{tabular}

schizophrenics and must be considered in light of this fact [24]. This may explain why the results of experimental investigations on semantic memory organization and retrieval in schizophrenics are so heterogeneous. And namely why, as in fluency, we can't still be sure of whatever impairments are matter of storing ([45-48]) or access $([49,50])$.

Some of the indexes are not concerned by significant differences between groups: average numbers of perseverations, rule breaks and average latencies. As inhibittion impairments have been largely emphasized in schizophrenics $([51,52])$, we should have seen significant differences for these indexes, at least perseveration and rule breaks. We argue that this could be due to the characteristics of our experimental sample. Indeed, we choose "stable" subjects to constitute our experimental group. We can think that in a larger and more heterogeneous sample, we would have observed different behaviors.

With regards to the dissociation of automatic versus controlled processes, we highlighted the fact that schizophrenics, as controls, exhibit lower performance for the second minute of production. This seems rational, knowing that controlled processes are effortful and that strategies that are under cognitive control will obviously take more time than automatic processes. Nevertheless our results also suggest larger and different impairments in schizophrenics, controlled processes being even lower for category fluency in those subjects.This seems surprising according to the greater impairments we found for letter fluency in schizophrenics but could indicate that the total scores provide only part of the information on the processes and strategies that are displayed to solve this type of task.

Concerning the link between executive dysfunctions and verbal and non-verbal fluency scores, only schizophrenics' results show significant correlations between the executive score (total FAB score) and all types of fluency scores (verbal and non-verbal). These results are not consistent with another study [18] which is the closer to ours and concludes that neither executive functioning nor working memory predict verbal fluency in schizophrenics, whereas, in healthy subjects, these variables do predict fluency scores. Nevertheless, there could be several explanations for these differences. First, these authors only consider the semantic version of the fluency task; while we analyzed fluency in a more general way, and try to intend fluency through its general and specific mechanisms. Secondly, they assessed executive functioning with several tests that require long or fractured testing. We opted for a global and brief executive measure that helps avoid timing bias.

Concerning symptomatology, our results are consistent with previous literature indicating that fluency impair- 
ments, in terms of a lower production, are rather linked with negative symptoms ([22,24,27-29]); while positive symptoms are rather connected with errors and perseverations. This last result, however, is not replicated in this study.

Although it may seem obvious that schizophrenics' performances in tasks that require efficiency such as verbal and non-verbal fluency are related to both executive functioning and symptoms, we think that this study brings an overall view of the interactions that those components may have. These analyzes can be integrated into a behavioral model with a double triangular canvas where the components related to the efficiency and implementation of strategies (fluency and executive functions) attract each other while opposing positive and yet more negative symptoms, especially when the behavior is mediated by a purely semantic information.

Figure 4 aims to summarize the multiple influences we raise from the Principal Component Analysis. We outlined the variables in four main concepts from the correlations matrix: fluency (non-verbal fluency, category fluency, letter fluency), executive functions (total FAB, motor programming, reasoning, interference, inhibition, environmental autonomy, mental flexibility), positive symptoms (positive scale score, positive factor score, disorganization factor score, duration of illness, general psychopathology score) and negative symptoms (negative scale score, negative factor score, social amotivation, core negative symptoms). The black triangle shows the pattern of interaction with the negative symptoms as main concept. In this pattern, efficiency components (executive function and fluency) are negatively correlated with positive symptoms and more negatively correlated with negative symptoms; while positive and negative symptoms also correlate negatively. The red triangle shows the pattern of interaction with executive functions as a main concept. In this pattern fluency and negative symptoms are grouped in the same cluster even

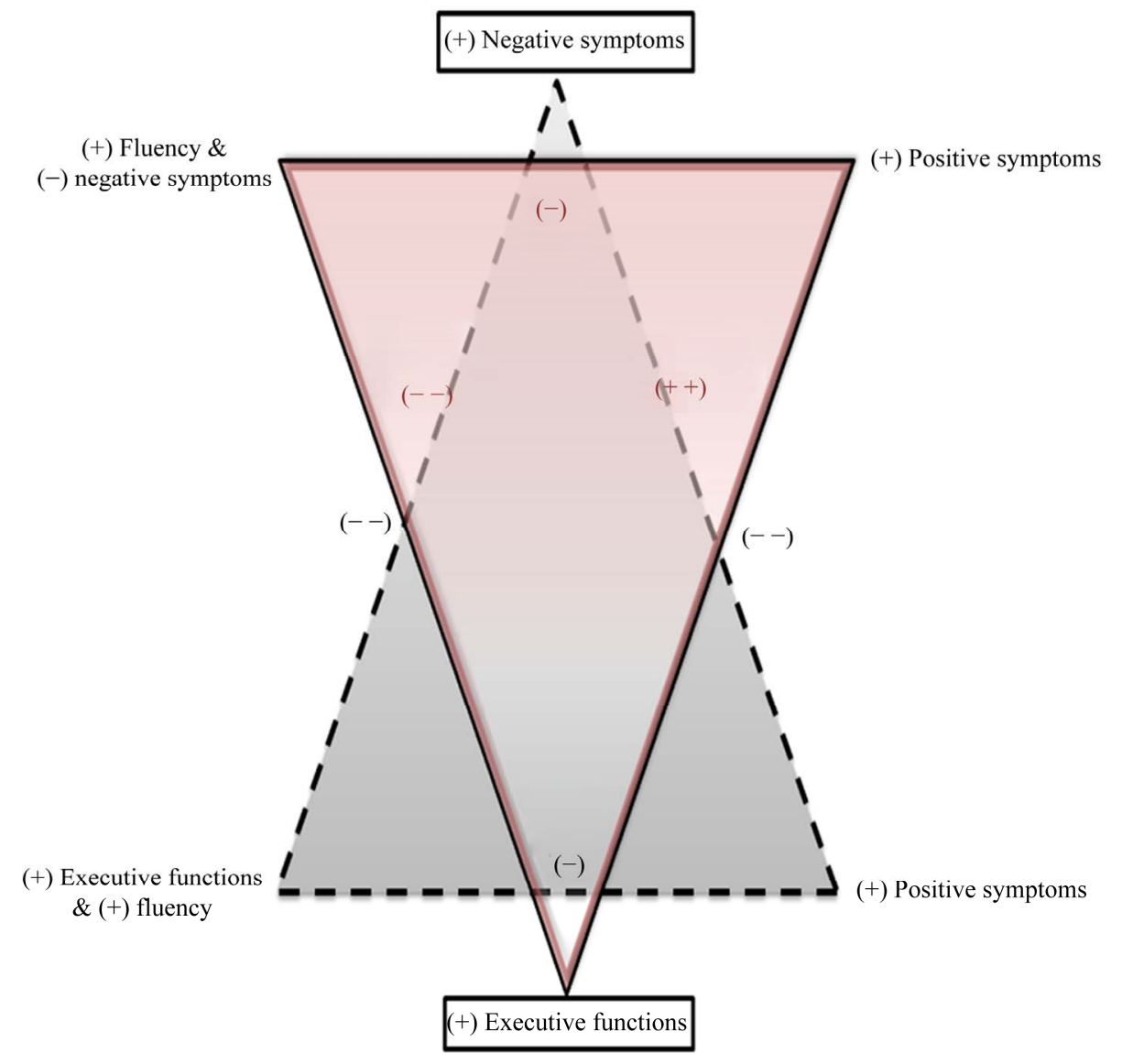

Figure 4. Triangular model of interaction. "+" and "-" signals refer to the valence of the correlations between the groups of variables/concepts; single signals refer to a short distance and doubled signals refer to a long distance between the concept in the factorial spaces. The distance should be interpreted in terms of attraction and repulsion between two or more concepts. Concepts that define the plan are pictured in a frame, on the apex of each triangle. Each triangle refers to a single plan, the plans are superimposed and the interactions have consequently no particular meaning for the interpretations. 
if they correlate negatively, this cluster being itself negatively linked with positive symptoms. This means that positive and negative symptoms correlate positively (-/-) while fluency and positive symptoms are negatively correlated $(-/+)$. Besides, executive functioning is more negatively correlated with positive symptoms and positively correlated with the fluency/negative symptoms clusters. This mean that executive functions correlate positively with fluency $(+/+)$ and negatively with negative symptoms $(+/-)$.

Finally, this study also emphasizes the interest of the non-verbal fluency task as a clinical and diagnostic tool on schizophrenics and brings an additional view of the interpretation of fluency tasks in this pathology. In the light of a triangular model as the one we mentioned, it seems clear that fluency in its global meaning is a really complex and multidimensional task that may have a specific diagnostic value in schizophrenia.

\section{REFERENCES}

[1] Troyer, A.K., Moscovitch, M. and Winocur, G. (2002) Clustering and switching as two components of verbal fluency: Evidence from younger and older healthy adults. Neuropsychology, 11, 138-146. http://dx.doi.org/10.1037/0894-4105.11.1.138

[2] Bozikas, V.P., Kosmidis, M.H. and Karavatos, A. (2005) Disproportionate impairment in semantic verbal fluency in schizophrenia: Differential deficit in clustering. Schizophrenia research, 74, 51-59. http://dx.doi.org/10.1016/j.schres.2004.05.001

[3] Troyer, A.K., Moscovitch, M., Winocur, G., Alexander, M.P. and Stuss, D. (1998) Clustering and switching on verbal fluency: The effects of focal frontal- and temporal-lobe lesions. Neuropsychologia, 36, 499-504. http://dx.doi.org/10.1016/S0028-3932(97)00152-8

[4] Cattelani, R., Dal Sasso, F., Corsini, D. and Posteraro, L. (2011) The Modified Five-Point Test: Normative data for a sample of Italian healthy adults aged 16-60. Neurological Sciences: Official Journal of the Italian Neurological Society and of the Italian Society of Clinical Neurophysiology, 32, 595-601. http://dx.doi.org/10.1007/s10072-011-0489-4

[5] Goebel, S., Fisher, R., Ferstl, R. and Medhorn, H.M. (2009) Normative data and psychometric properties for qualitative and quantitative scoring criteria of the Fivepoint Test. The Clinical Neuropsychologist, 29, 675-690. http://dx.doi.org/10.1080/13854040802389185

[6] Ruff, R.M., Light, R.H. and Evans, R.W. (1987) The ruff figural fluency test: A normative study with adults. Developmental Neuropsychology, 3, 37-51. http://dx.doi.org/10.1080/87565648709540362

[7] Tucha, L., Aschenbrenner, S., Koerts, J. and Lange, K.W. (2012) The five-point test: Reliability, validity and normative data for children and adults. PloS one, 7, Article ID: e46080.

http://dx.doi.org/10.1371/journal.pone.0046080
[8] Goebel, S., Atanassov, L., Köhnken, G., Mehdorn, H.M. and Leplow, B. (2012) Understanding quantitative and qualitative figural fluency in patients with Parkinson's disease. Neurological Sciences, 34, 1383-1390. http://dx.doi.org/10.1007/s10072-012-1245-0

[9] Phillips, T.J., James, A.C.D., Crow, T.J. and Collinson, S.L. (2004) Semantic fluency is impaired but phonemic and design fluency are preserved in early-onset schizophrenia. Schizophrenia research, 70, 215-222. http://dx.doi.org/10.1016/j.schres.2003.10.003

[10] Bokat, C.E. and Goldberg, T.E. (2003) Letter and category fluency in schizophrenic patients: A meta-analysis. Schizophrenia Research, 64, 73-78. http://dx.doi.org/10.1016/S0920-9964(02)00282-7

[11] Ojeda, N., Sánchez, P., Peña, J., Elizagárate, E., Yoller, A.B., Larumbe, J., Gutiérrez, M., et al. (2010) Verbal fluency in schizophrenia: Does cognitive performance reflect the same underlying mechanisms in patients and healthy controls? Journal of Nervous and Mental Disease, 198, 286-291. http://dx.doi.org/10.1097/NMD.0b013e3181d61748

[12] Juhasz, B.J., Chambers, D., Shesler, L.W., Haber, A. and Kurtz, M.M. (2012) Evaluating lexical characteristics of verbal fluency output in schizophrenia. Psychiatry Research, 200, 177-183.

http://dx.doi.org/10.1016/j.psychres.2012.06.035

[13] Birn, R.M., Kenworthy, L., Case, L., Caravella, R., Jones, T.B., Bandettini, P.A and Martin, A. (2010) Neural systems supporting lexical search guided by letter and semantic category cues: A self-paced overt response fMRI study of verbal fluency. NeuroImage, 49, 1099-1107. http://dx.doi.org/10.1016/j.neuroimage.2009.07.036

[14] Hirshorn, E.A. and Thompson-Schill, S.L. (2006) Role of the left inferior frontal gyrus in covert word retrieval: Neural correlates of switching during verbal fluency. Neuropsychologia, 44, 2547-2557.

http://dx.doi.org/10.1016/j.neuropsychologia.2006.03.035

[15] Henry, J.D. and Crawford, J.R. (2005) A meta-analyticreview of verbal fluencydeficits in schizophrenia relative to other neurocognitive deficits. Cognitive Neuropsychiatry, 10, 1-33.

http://dx.doi.org/10.1080/13546800344000309

[16] Berenbaum, H., Kerns, J.G., Vernon, L.L. and Gomez, J.J. (2008) Cognitive correlates of schizophrenia signs and symptoms: I. Verbal communication disturbances. Psychiatry Research, 159, 47-56. http://dx.doi.org/10.1016/j.psychres.2007.08.016

[17] Joyce, E.M., Collinson, S.L. and Crichton, P. (1996) Verbal fluency in schizophrenia: relationship with executive function, semantic memory and clinical alogia. Psychological Medicine, 26, 39-49. http://dx.doi.org/10.1017/S0033291700033705

[18] Van Beilen, M., Pijnenbord, M., Van Zomeren, E.H., Van den Bosch, R.J., Withaar, F. and Bouma, A. (2004) What is measured by verbal fluency tasks in schizophrenia. Schizophrenia Research, 69(, 267-276. http://dx.doi.org/10.1016/j.schres.2003.09.007

[19] Sumiyoshi, C., Matsui, M., Sumiyoshi, T., Yamashita, I., Sumiyoshi, S. and Kurachi, M. (2001) Semantic structure 
in schizophrenia as assessed by the category fluency test: Effect of verbal intelligence and age of onset. Psychiatry Research, 105, 187-199. http://dx.doi.org/10.1016/S0165-1781(01)00345-6

[20] Kosmidis, M.H., Bozikas, V.P., Vlahou, C.H., Kiosseoglou, G., Giaglis, G. and Karavatos, A. (2005) Verbal fluency in institutionalized patients with schizophrenia: Age-related performance decline. Psychiatry Research, 134, 233-240.

http://dx.doi.org/10.1016/j.psychres.2005.02.003

[21] Sumiyoshi, C., Sumiyoshi, T., Matsui, M., Nohara, S., Yamashita, I., Kurachi, M. and Niwa, S. (2004) Effect of orthography on the verbal fluency performance in schizophrenia: Examination using Japanese patients. Schizophrenia Research, 69, 15-22. http://dx.doi.org/10.1016/S0920-9964(03)00174-9

[22] Woodward, T.S., Ruff, C.C., Thornton, A.E., Moritz, S. and Liddle, P.F. (2003) Methodological considerations regarding the association of Stroop and verbal fluency performance with the symptoms of schizophrenia. Schizophrenia Research, 61, 207-214. http://dx.doi.org/10.1016/S0920-9964(02)00211-6

[23] Bejaoui, M. and Pedinielli, J.-L. (2010) Flexibilité cognitive, attention sélective et fluidité verbale sémantique dans trois dimensions de schizophrénie: Psychotique, négative et de désorganisation. Pratiques Psychologiques, 16, 259-272. http://dx.doi.org/10.1016/j.prps.2009.04.007

[24] Frith, C.D. (1992) The Cognitive Neuropsychology of Schizophrenia (Psychology). Psychology Press, London.

[25] Docherty, A.R., Berenbaum, H. and Kerns, J.G. (2011) Alogia and formal thought disorder: Differential patterns of verbal fluency task performance q. Journal of Psychiatric Research, 45, 1352-1357.

http://dx.doi.org/10.1016/j.jpsychires.2011.04.004

[26] Rossell, S.L., Rabe-Hesketh, S.S., Shapleske, J.S. and David, A.S. (1999) Is semantic fluency differentially impaired in schizophrenic patients with delusions? Journal of Clinical and Experimental Neuropsychology, 21, 629642. http://www.ncbi.nlm.nih.gov/pubmed/10572283 http://dx.doi.org/10.1076/jcen.21.5.629.865

[27] Brébion, G., Villalta-Gil, V., Autonell, J., Cervilla, J., Dolz, M., Foix, A., Haro, J.M., et al. (2013) Cognitive correlates of verbal memory and verbal fluency in schizophrenia, and differential effects of various clinical symptoms between male and female patients. Schizophreniaresearch, 147, 81-85. http://dx.doi.org/10.1016/j.schres.2013.03.014

[28] Robert, P.H., Thauby, S., Migneco, V., Chaix, I., Caci, H., Benoit, M., Pringuey, D., et al. (1996) Neurocognitive subtypes of schizophrenia according to performance at verbal fluency tasks. L'Encéphale, 22, 435-442.

[29] Ziauddeen, H., Dibben, C., Kipps, C., Hodges, J.R. and McKenna, P.J. (2011) Negative schizophrenic symptoms and the frontal lobe syndrome: one and the same? European Archives of Psychiatry and Clinical Neuroscience, 261, 59-67.

[30] Pegoraro, L.F.L., Dantas, C.R., Banzato, C.E.M. and Fuentes, D. (2013) Correlation between insight dimensions and cognitive functions in patients with deficit and nondeficit schizophrenia. Schizophrenia Research, 147, 91-94. http://dx.doi.org/10.1016/j.schres.2013.02.041

[31] Chen, R.Y., Chen, E.Y., Chan, C.K., Lam, L.C. and LiehMak, F. (2000) Verbal fluency in schizophrenia: Reduction in semantic store. The Australian and New Zealand Journal of Psychiatry, 34, 43-48. http://dx.doi.org/10.1046/j.1440-1614.2000.00647.x

[32] Hu, M., Chen, J., Li, L., Zheng, Y., Wang, J., Guo, X., $\mathrm{Wu}, \mathrm{R}$., et al. (2011) Semantic fluency and executive functions as candidate endophenotypes for the early diagnosis of schizophrenia in Han Chinese. Neuroscience Letters, 502, 173-177. http://dx.doi.org/10.1016/j.neulet.2011.07.037

[33] American Psychiatric Association (2000) Diagnostic and statistical manual of mental disorders. 4th Edition, APA, Washington DC.

[34] Cardebat, D., Doyon, B., Puel, M., Goulet, P. and Joanette, Y. (1990) Evocation lexicale formelle et sémantique chez des sujets normaux: Performances et dynamiques de production en fonction du sexe, de l'âge et du niveau d'étude. Acta Neurologica Belgica, 90, 207-217.

[35] Dubois, B., Slachevsky, A., Litvan, I. and Pillon, B. (2000) The FAB: A frontal assessment battery at bedside. Neurology, 55, 1621-1626. http://dx.doi.org/10.1212/WNL.55.11.1621

[36] Cunha, P.J., Nicastri, S., De Andrade, A.G. and Bolla, K.I. (2010) The frontal assessment battery (FAB) reveals neurocognitive dysfunction in substance-dependent individuals in distinct executive domains: Abstract reasoning, motor programming, and cognitive flexibility. Addictive behaviors, 35, 875-881. http://dx.doi.org/10.1016/j.addbeh.2010.05.005

[37] Nimatoudis, I., Spyridi, S., Kantartzis, S., Sokolaki, S., Panagiotidis, P., Nassika, Z. and Kaprinis, G. (2007) The frontal assessment battery at bedside (FAB) in patients with schizophrenia. European Psychiatry, 22, S128. http://dx.doi.org/10.1016/j.eurpsy.2007.01.411

[38] Kay, S.R., Fiszbein, A. and Opler, L.A. (1987) The positive and negative syndrome scale (PANSS) for schizophrenia. Schizophrenia Bulletin, 13, 261-276. http://dx.doi.org/10.1093/schbul/13.2.261

[39] Lépine, J.-P. and Perretti, C.S. (2008) Positive and negative syndrome scale. Editions médicales Pierre Fabre, Paris.

[40] Bell, M.D., Lysaker, P.H., Beam-Goulet, J.L., Milstein, R. M. and Lindenmayer, J.P. (1994) Five-component model of schizophrenia: Assessing the factorial invariance of the positive and negative syndrome scale. Psychiatry Research, 52, 295-303.

http://dx.doi.org/10.1016/0165-1781(94)90075-2

[41] Liemburg, E., Castelein, S., Stewart, R., Van der Gaag, M., Aleman, A. and Knegtering, H. (2013) Two subdomains of negative symptoms in psychotic disorders: Established and confirmed in two large cohorts. Journal of Psychiatric Research, 47, 1-8. http://dx.doi.org/10.1016/j.jpsychires.2013.01.024

[42] Allen, H.A., Liddle, P.F. and Frith, C.D. (1993) Negative features, retrieval processes and verbal fluency in schizophrenia. British Journal of Psychiatry, 73, 769- 
775. http://dx.doi.org/10.1192/bjp.163.6.769

[43] Heinrichs, D.W. and Zakzanis, K. (1998) Neurocognitive deficits in schizophrenia: A quantitative review of the evidence. Neuropsychology, 12, 426-445.

http://dx.doi.org/10.1037/0894-4105.12.3.426

[44] O'Carroll, R. (2000) Cognitive impairment in schizophrenia. Advances in Psychiatric Treatment, 6, 161-168. http://dx.doi.org/10.1192/apt.6.3.161

[45] Kiang, M., Christensen, B.K., Kutas, M. and Zipursky, R. B. (2012) Electrophysiological evidence for primary semantic memory functional organization deficits in schizophrenia. Psychiatry Research, 196, 171-180. http://dx.doi.org/10.1016/j.psychres.2012.02.026

[46] Laws, K.R., Al-Uzri, M. and Mortimer, A.M. (2000) Lexical knowledge degradation in schizophrenia. Schizophrenia Research, 45, 123-131. http://dx.doi.org/10.1016/S0920-9964(99)00184-X

[47] Moelter, S.T., Hill, S.K., Hughett, P., Gur, R.C., Gur, R.E. and Ragland, J.D. (2005) Organization of semantic category exemplars in schizophrenia. Schizophrenia Research, 78, 209-217. http://dx.doi.org/10.1016/j.schres.2005.06.011

[48] Niznikiewicz, M., Mittal, M.S., Nestor, P.G. and McCarley, R.W. (2010) Abnormal inhibitory processes in se- mantic networks in schizophrenia. International Journal of Psychophysiology, 75, 133-140.

http://dx.doi.org/10.1016/j.ijpsycho.2009.10.006

[49] Al-Uzri, M., Laws, K.R. and Mortimer, A.M. (2004) An early marker for semantic memory impairment in patients with schizophrenia. Cognitive Neuropsychiatry, 9, $267-$ 279. http://dx.doi.org/10.1080/13546800344000255

[50] Doughty, O.J. and Done, D.J. (2009) Is semantic memory impaired in schizophrenia? A systematic review and meta-analysis of 91 studies. Cognitive Neuropsychiatry, 14, 473-509. http://dx.doi.org/10.1080/13546800903073291

[51] Joshua, N., Gogos, A. and Rossell, S. (2009) Executive functioning in schizophrenia: A thorough examination of performance on the Hayling Sentence Completion Test compared to psychiatric and non-psychiatric controls. Schizophrenia research, 114, 84-90. http://dx.doi.org/10.1016/j.schres.2009.05.029

[52] Weisbrod, M., Kiefer, M., Marzinzik, F. and Spitzer, M. (2000) Executive control is disturbed in schizophrenia: Evidence from event-related potentials in a $\mathrm{Go} / \mathrm{NoGo}$ task. Biological Psychiatry, 47, 51-60. http://dx.doi.org/10.1016/S0006-3223(99)00218-8 